\title{
A CFD-based Nucleation-growth-removal Model for Inclusion Behavior in a Gas-agitated Ladle during Molten Steel Deoxidation
}

\author{
You-Jong KWON, ${ }^{11}$ Jian ZHANG ${ }^{21}$ and Hae-Geon LEE" ${ }^{11}$ \\ 1) Graduate Institute of Ferrous Technology (GIFT), Pohang University of Science and Technology (POSTECH), San 31 Hyoja- \\ dong, Pohang, 790-784, Korea. 2) Technology Center, Maanshan Iron \& Steel Co., Ltd., No. 8, Hunanxi Road,
} Maanshan, Anhui, China.

(Received on October 1, 2007; accepted on April 9, 2008)

\begin{abstract}
A coupled numerical model based on computational fluid dynamics (CFD), termed a CFD-based nucleation-growth-removal model, has been proposed to investigate the nucleation, growth and removal of inclusions in a bottom-blown gas-stirred ladle during molten steel deoxidation.

In order to account for the turbulent circulating flow induced by gas bubbling through the bottom, the $\kappa-\varepsilon$ turbulence model was employed to evaluate time-averaged Reynolds stress while the fluctuation of the free surface of the melt was traced by means of the VOF technique. This model enables to couple transient flow fields, and temperature fields with concentration fields of elements and inclusions in melt so that it can meet the requirements of evolution of time- and space-dependent particle size distributions (PSD) without any given initial PSD of inclusions but directly from chemical reaction.

The model was applied to the simulation of the molten steel deoxidation process in Fe-Al-O system in an argon gas-stirred ladle. The model successfully predicted important phenomena including turbulent recirculation flow patterns, streamline structure of steel melt, turbulence energy variation and its dissipation rate, transient temperature fields and particle size distributions of alumina inclusion. Comparison with some industrial data showed that the predicted PSDs were reasonable in time-dependent variation of inclusion size distribution.
\end{abstract}

KEY WORDS: numerical modeling; inclusion; particle size distribution (PSD); nucleation; growth; removal; CFD; gas bubbling.

\section{Introduction}

Inclusion behavior in molten steel, i.e., formation, growth and removal, has received much attention for decades due its vital effect on morphology, size and distribution of inclusions and further steel properties. Refining processes during the liquid steel stage of steelmaking involve a very complex multiphase system, in which many physical and chemical phenomena, such as fluid flow, heat and mass transfer, and high temperature chemical interactions simultaneously occur and contribute to the evolution of inclusions. This suggests an urgent necessity of development of a computational means which successfully combines thermodynamics and kinetics with hydrodynamics in order to ascertain the nature of inclusion in molten steel.

A review of the mathematical modeling history in inclusion engineering shows that considerable work has been done in various areas:

- Numerical models for fluid flow, heat and mass transfer, ${ }^{1-16)}$ which are subject to the conservation of momentum, heat and mass in a system. In these models, the $\kappa-\varepsilon$ two-equation turbulence model ${ }^{1)}$ is most commonly employed in order to solve the problem of time-averaged
Reynolds stress in a turbulent flow. As to bubble-driven flows, various quasi single-phase models ${ }^{2-7)}$ or two-phase models ${ }^{8-16)}$ are usually expected to be promising means.

- Analytical models for inclusion growth and removal, which provide a solid theoretical base for understanding of various growth and removal mechanisms. An important contribution can be traced to Lindborg and Torssell, ${ }^{17)}$ early in 1968 , who took into account Stokes and gradient collisions between particles and particle removal at the top surface of the bath in their model. Other important investigations include Iyengar and Philbrook, ${ }^{18)}$ Linder, ${ }^{19)}$ and Engh and Lingskog, ${ }^{20)}$ which discussed various collision growth approaches, such as turbulent, Stokes and gradient collisions.

- CFD-based coupled models for inclusion growth and removal: The development of turbulent models and computer technologies provides further possibilities to describe turbulent flow patterns more accurately in metallurgical containers by numerically solving conservation equations, and then to couple the kinetics equations of particle growth and the transport equations of inclusions in melt with CFD models. Important studies in this area include the work of Nakanishi and Szekely ${ }^{21)}$ (ASEA- 
SKF furnaces), that of Shirabe and Szekely, ${ }^{22)}$ Miki et $a .^{23)}$ (RH degassers), the predictions from Tozawa et al., ${ }^{24)}$ Miki et al., ${ }^{25)}$ and Sinha et al. ${ }^{26)}$ (tundish metallurgical processes), and more recent work by Sheng et al. ${ }^{27)}$ and Söder et al. $^{28)}$ (ladle refining). To activate the models, one need to input an initial size distribution of inclusions, which comes from either experimental measurements or assumptions, to provide a starting point for numerical calculations. Therefore, the results predicted by a model for inclusion growth and removal are dependent to some extent on the validity of the initial particle size distribution (PSD) selected.

- Theoretical models for the nucleation and growth of inclusions: Christian ${ }^{29)}$ gave a comprehensive review and summarization of the classical nucleation theories. Turpin and Elliott, ${ }^{30)}$ Turkdogan, ${ }^{31,32)}$ and Mukai et al. ${ }^{33)}$ applied the classical nucleation theories to steelmaking processes and analyzed inclusion formation and growth during molten steel deoxidation under a hypothesis of homogeneous nucleation. These theoretical models laid the foundation for the subsequent investigations.

- Static numerical models for nucleation, growth and removal of inclusion: Attempts to develop general nucleation-growth models for molten steel deoxidation were marked by the work of Zhang and Pluschkell, ${ }^{34)}$ Doo et $a l .{ }^{35)}$ and others. Although the model from the latter should virtually be a growth model rather than a real nucleation-growth model, Zhang and Pluschkell ${ }^{34)}$ borrowed ideas from Kampmann and Kahlweit, ${ }^{36)}$ and put forward a static numerical model, which is based on mean processing parameters, to predict particle nucleation time evolution, Ostwald ripening, and growth processes dominated by Brownian collisions and turbulent collisions.

On the basis of mean parameters, the present authors proposed a general nucleation-growth model ${ }^{37)}$ in order to investigate inclusion behaviors during molten steel deoxidation. The model covers a deoxidation process from inclusion nucleation to growth, and considers the homogeneous nucleation theory and various collision-coagulation mechanisms, utilizing an approximate numerical method, the DS method. ${ }^{37)}$ However, in a practical refining process, variables describing molten steel properties such as flow parameters, temperature, chemical concentration, and even density and viscosity, are functions of time and space. On the other hand, the size distribution of inclusions, i.e., deoxidation reaction products, varies with time as well as spatial location due to the transport phenomena of inclusions in molten steel. Obviously, it is necessary for fluid dynamics to be coupled with the nucleation-growth model to account for any real deoxidation process. Therefore, the present work is addressed to extend the static nucleation-growth model to a more practical level, a dynamic nucleationgrowth-removal model, in a CFD framework. The model considers inclusion nucleation and growth mechanisms as well as removal approaches, and is based on ever-changing, prevailing thermodynamic and hydrodynamic conditions rather than a mean parameter system of molten steel. Certainly, the PSD of inclusions originates directly from deoxidation reactions; no initial PSD is necessary to activate the model.

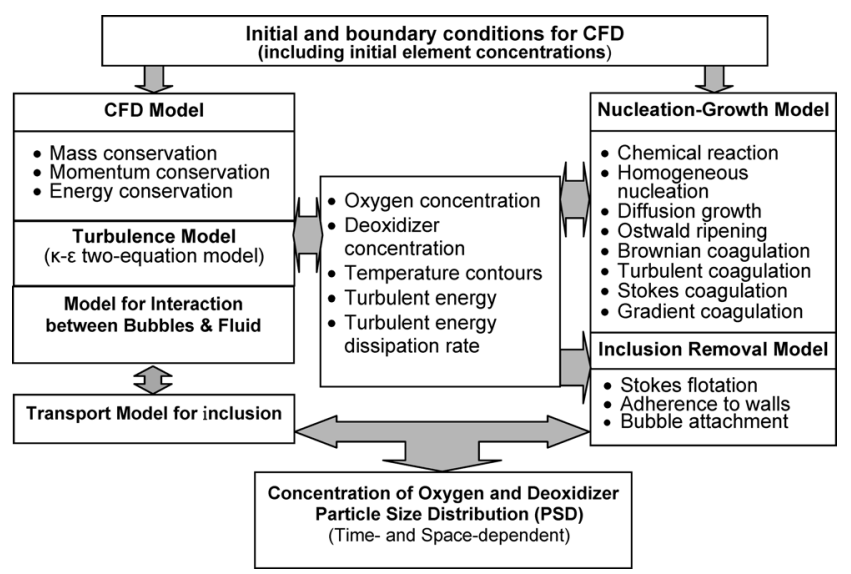

Fig. 1. Ideas and structure of the CFD-based nucleation-growthremoval model.

In this paper, the ideas of model structure are recounted firstly, followed by the establishment of CFD model and the description of homogeneous nucleation, growth and removal mechanisms, and a discussion is given on some aspects of the theoretical model. Results of the application of the dynamic model are presented and detailed discussion is then followed.

\section{Main Ideas and Model Structure}

The basic ideas of the present model are schematically structured in Fig. 1. The entire model consists of two main blocks; i.e., a CFD model block and an inclusion nucleation-growth-removal model block. The CFD model is established on the platform of the general-purpose FLOW$3 \mathrm{D}^{\circledR}$ code, which can be employed to predict flow patterns, temperature fields and turbulence parameters according to the conservation of mass, energy and momentum and with the $\kappa-\varepsilon$ two-equation turbulence model. The inclusion nucleation-growth-removal model is structured to start from the initial deoxidation reaction and then proceed to homogeneous nucleation, diffusion growth and Ostwald ripening, and simultaneously evaluates various collision-coagulation growth as well as removal.

In each computing iteration, melt temperatures, oxygen concentration, deoxidizer concentrations and turbulence parameters, produced by the CFD model, are fed into the inclusion model. PSDs of inclusion, as an output of the latter, are fed back again to the CFD model, where an inclusion transport model further calculates space-dependent PSDs. As the final result is computed, a time- and space-dependent inclusion size distribution is expected.

In the model development, the deoxidation reaction in the $\mathrm{Fe}-\mathrm{M}-\mathrm{O}$ melt bath is assumed to follow the stoichiometric reaction as given in Eq. (1):

$$
n[\mathrm{M}]+m[\mathrm{O}]=\mathrm{M}_{n} \mathrm{O}_{m}
$$

The model is developed based on the number of predetermined conditions and assumptions which are inevitably necessary to produce numerical results. These conditions and assumptions are given in Table $\mathbf{1}$. 
Table 1. Conditions and assumptions employed in the model development.

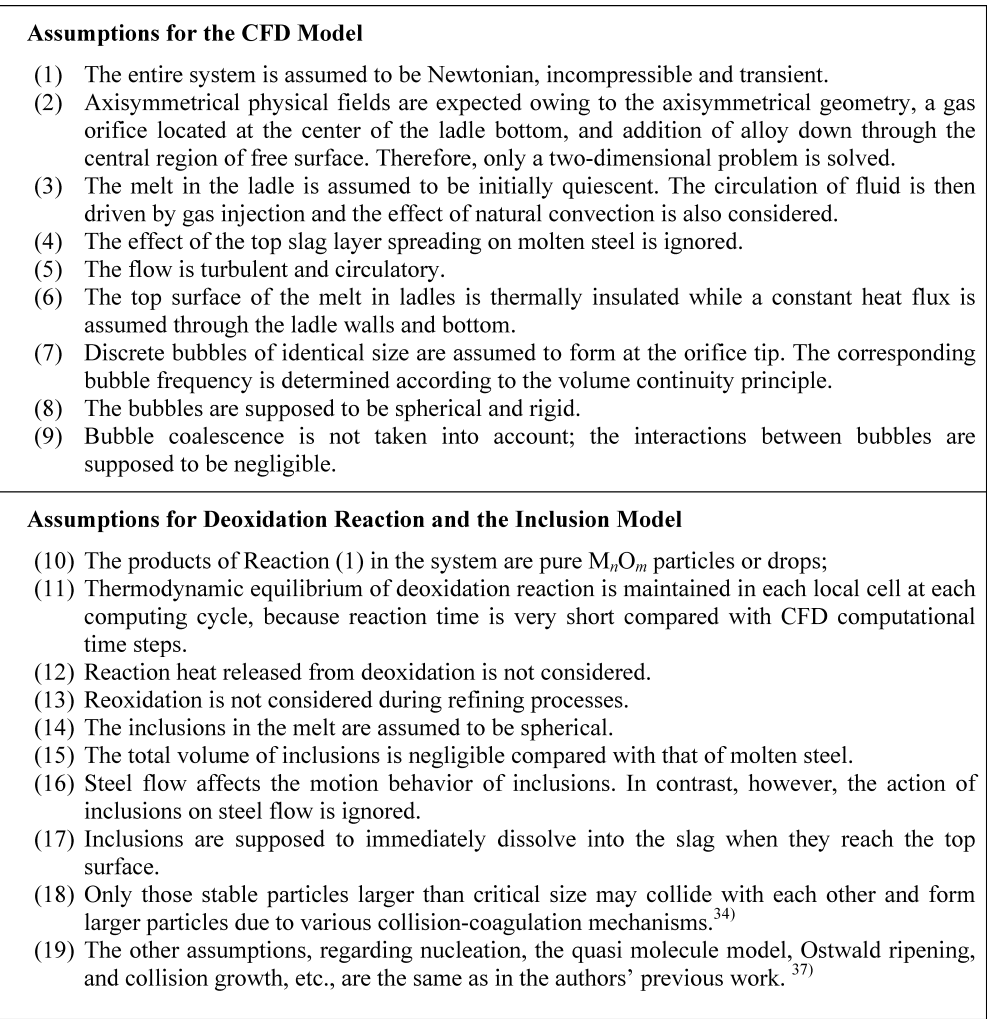

\section{Modeling for Inclusion Nucleation, Growth and Re- moval}

The time evolution of the deoxidation process based on the reaction of Eq. (1), after the addition of a deoxidant into the bulk of molten steel, is believed to consist of several stages: 1) deoxidation reaction and formation of nuclei with critical sizes from reaction products ${ }^{37)}$; 2) Ostwald ripening or coarsening process of nuclei; 3 ) collision and coagulation growth, i.e., Brownian collision, turbulent collision, Stokes collision, and gradient collision; 4) removal of inclusions by Stokes flotation, wall attachment and bubbleinclusion attachment. The above steps may proceed simultaneously.

\subsection{Homogeneous Nucleation and Ostwald Ripening}

The present authors have previously proposed a so-called quasi molecule model to describe homogeneous nucleation, diffusion growth and Ostwald ripening during deoxidation. ${ }^{37)}$ The same model is employed in the present approach. Mathematically, the dynamics of inclusion size distribution during nucleation, diffusion growth and coarsening is represented by Eq. (2), which accommodates the reversed dissociation of inclusions by following Kampmann and Kahlweit. ${ }^{36)}$

$$
\begin{aligned}
S_{p}^{N O}= & \frac{d n_{k}}{d t}=\beta_{1, k-1} n_{1} n_{k-1} /(1+\delta(k=2))-\beta_{1 k} n_{1} n_{k} \\
& +\alpha_{k+1} A_{k+1} n_{k+1}-\alpha_{k} A_{k} n_{k}, \quad \text { for } k=2,3 \ldots \ldots
\end{aligned}
$$

where, the first term on the right side represents the generation rate of $k$-mers by addition of a monomer to a $(k-1)$ mer, the second term the depletion rate of $k$-mers resulting from the formation of $(k+1)$-mers by assembling of a $k$-mer and a monomer, the third the formation of $k$-mers when a $(k+1)$-mer loses a monomer by dissociation, the last term the dissipation of $k$-mers caused by losing a monomer from a $k$-mer, and $n_{k}\left(\mathrm{n} \cdot \mathrm{m}^{-3}\right)$ the number density of $k$-size particles or embryos ( $k$-mers), $n_{s}\left(\mathrm{n} \cdot \mathrm{m}^{-3}\right)$ the number density of total monomers including those in embryos and particles, $\beta_{1 k}\left(\mathrm{~m}^{3} \cdot \mathrm{s}^{-1}\right)$ the rate constant of the reaction $(1)+(k) \rightarrow$ $(k+1), \alpha_{k}\left(\mathrm{~m}^{-2} \cdot \mathrm{s}^{-1}\right)$ the dissociation rate of a $k$-size particle, and $A_{k}\left(\mathrm{~m}^{2}\right)$ the surface area of a $k$-size particle. The Dirac delta function $\delta(k=2)$ has a value of 1 when $k=2$, otherwise it is equal to zero.

\subsection{Collision-coagulation Growth}

A mathematical description of the evolution of PSDs due to collisions between particles should be based on the population balance equation given below, which was proposed by Smoluchowski ${ }^{38)}$;

$$
\begin{aligned}
S_{p}^{C} & =\frac{d n_{k}}{d t}=\frac{1}{2} \sum_{i=i_{c}, i+j=k}^{k-i_{c}} f_{i j}-\sum_{i=i_{c}}^{\infty} f_{i k} \\
& =\frac{1}{2} \sum_{i=i_{c}, i+j=k}^{k-i_{c}} \beta_{i j}^{C} n_{i} n_{j}-\sum_{i=i_{c}}^{\infty} \beta_{i k}^{C} n_{i} n_{k}, \quad \text { for } k \geq 2 i_{c}
\end{aligned}
$$

in terms of the so-called collision frequency $f_{i j}\left(\mathrm{~m}^{-3} \cdot \mathrm{s}^{-1}\right)$, collision frequency function $\beta_{i j}^{C}\left(\mathrm{~m}^{3} \cdot \mathrm{s}^{-1}\right.$ ) (also termed collision volume or the degree of collision), particle number density $n\left(\mathrm{~m}^{-3}\right)$ (particle number per unit volume), and time $t$. The subscripts $i, j$ and $k$ imply embryos or inclusions assembled by $i, j$ and $k$ number of monomers, i.e., $i$-mer, $j$ mer and $k$-mer, respectively. And the superscript $C$ means 'collision'. When it is replaced by ' $B$ ', ' $T$ ', ' $S$ ' and ' $G$ ' sequentially, the relevant parameters are related to Brownian collision, ${ }^{39)}$ turbulent collision, ${ }^{40)}$ Stokes collision, ${ }^{17)}$ and 
gradient collision, ${ }^{17,41)}$ respectively. The first term on the right hand side of Eq. (3) stands for the generation of particle $k$ due to the collision of two smaller particles $i$ and $j$, and the second term the dissipation of particle $k$ due to collision growth. The contributions to time-dependent PSD from different collision mechanisms can be represented by the corresponding collision frequency function $\beta_{i j}^{C}$ in following sections.

\subsection{Inclusion Removal}

The main routes which remove inclusions from the molten steel in ladle systems include the Stokes flotation of inclusions upward to the top slag, adherence to walls and bubble-inclusion attachment.

\subsubsection{Stokes Flotation}

Based on assumption (17), the inclusion removal flux through the free surface due to flotation $S_{p}^{F}$ is dependent on inclusion concentration $n_{i}\left(\mathrm{~m}^{-3}\right)$ near the surface and the floating velocity of inclusions $u_{p}\left(\mathrm{~m} \cdot \mathrm{s}^{-1}\right)$. Here, the floating velocity is calculated from Stokes' law. In the numerical model, Eq. (4) is employed to formulate the rate of the change in the inclusion number density in surface boundary cells due to the effect of flotation in terms of the local fluid height $h$.

$$
S_{p}^{F}=-n_{i} \cdot u_{p} / h
$$

\subsubsection{Adherence to Walls}

Linder, ${ }^{19)}$ Sinha et al. ${ }^{26)}$ and Sheng et al. ${ }^{27)}$ proposed models to account for the removal of inclusions to refractory walls by help of the boundary layer theory. According to Sheng et al., ${ }^{27)}$ as inclusion approaches to the wall, the probability of wall-inclusion attachment increases, and becomes one when the inclusion is within a critical distance to the wall. Following their treatment, the wall adherence model is mathematically represented as follows:

$$
\begin{gathered}
\eta_{W A}= \begin{cases}1.0, & y^{+} \leq 11.63 \\
1-\delta / y, & y^{+}>11.63\end{cases} \\
\delta=\frac{10 v_{l}}{\sqrt{\left(\tau_{0} / \rho_{l}\right)}} \approx \frac{10 v_{l}}{C_{\mu}^{0.25} \kappa^{0.5}} . \\
y^{+}=\frac{y \sqrt{\left(\tau_{0} / \rho_{l}\right)}}{v_{l}}=\frac{10 y}{\delta} \cdots
\end{gathered}
$$

where $\eta_{W A}$ is theremoval efficiency of inclusions, $\delta(\mathrm{m})$ the boundary layer thickness, $y^{+}$the dimensionless distance from the wall in the law of the wall, with reference to the distance from the wall $y(\mathrm{~m})$, shear stress $\tau_{0}\left(\mathrm{~kg} \cdot \mathrm{m}^{-1} \cdot \mathrm{s}^{-2}\right)$, turbulent energy $\kappa\left(\mathrm{m}^{2} \cdot \mathrm{s}^{-2}\right)$, fluid density $\rho_{l}\left(\mathrm{~kg} \cdot \mathrm{m}^{-3}\right)$, time $t$, calculation time step $\delta_{t}(\mathrm{~s})$, and kinematic viscosity $v_{l}$ $\left(\mathrm{m}^{2} \cdot \mathrm{s}^{-1}\right)$. Hence, the inclusion removal flux through wall $S_{p}^{W A}$ has

$$
\int_{0}^{\delta t} S_{p}^{W A} d t=-n_{k} \eta_{W A}
$$

When $\eta_{W A}$ equals to 1 , all the inclusions in the region will be removed by wall-inclusion attachment.

\subsubsection{Bubble Attachment}

In the authors' previous work, ${ }^{42)}$ the force field model was proposed to simulate bubble-inclusion attachment. This model was developed through the combination of Frisvold model $^{43)}$ and force field concept. ${ }^{42)}$

$$
\begin{gathered}
P_{C}=\frac{3}{2}\left(\frac{1}{94}\right)^{2} \sqrt{\frac{3}{2} R e} \approx 2.08 \times 10^{-4} \sqrt{R e} \\
\quad\left(\text { when } \frac{r_{P}}{r_{B}} \ll 1\right) \\
\frac{d N}{d t}=P_{C} \pi\left(r_{b}+r_{p}\right)^{2} v_{b} C_{i} N_{B} \ldots \ldots \ldots \ldots \ldots \ldots
\end{gathered}
$$

where $N$ is number of bubble-inclusion collision, $t$ time, $P_{C}$ probability of collision, $r_{b}$ radius of bubble, $r_{p}$ radius of particle, i.e., inclusion, $v_{b}$ is velocity of bubble and $R e$ Reynolds number of bubble.

\section{Simulation of Deoxidation in a Ladle}

The deoxidation process of the molten steel using aluminum in a ladle stirred by argon gas from the bottom was simulated to describe:

(1) transient fluid flow which is characterized by the evolution of flow patterns, stream lines, turbulent parameters, etc.,

(2) thermal homogenization with the variation of temperature fields in the steel melt,

(3) mass homogenization process accompanied by $\mathrm{Al}-\mathrm{O}$ reaction in the steel melt, providing time-dependent distributions of aluminum and oxygen concentrations,

(4) space- and time-dependent particle size distributions (PSDs) as well as relevant bulk-averaged data,

(5) comparison of predicted distribution trend of PSD with industrial measurements,

(6) effect of gas bubbling on the inclusion removal.

\subsection{Conditions of Al Deoxidation Process}

The CFD-based Nucleation-Growth and Removal model was applied to the case in that 250 tons of molten steel with $300 \mathrm{ppm}$ oxygen in a ladle, which measures $3.58 \mathrm{~m}$ in diameter and $3.57 \mathrm{~m}$ in depth. Initially, the molten steel is motionless and has a uniform oxygen distribution, but there is a thermal stratification, i.e., a linear temperature gradient of $40^{\circ} \mathrm{C}$ the vertical direction with a maximum temperature of $1580^{\circ} \mathrm{C}$ at the top surface and a minimum value of $1540^{\circ} \mathrm{C}$ at the ladle bottom. During the refining process, heat loss is assumed to occur through the sidewall and ladle bottom while the top surface is thermally insulated. Argon gas is introduced into the ladle through a center-located bottom orifice. Aluminum is added into the steel melt through the center area at the top surface 3 min after the start of bubbling, at which a stable recirculation is expected to form in the liquid pool. Figure 2 illustrates the gas-stirred steel ladle. Detailed processing variables and the relevant parameters employed in the simulation are listed in Table 2.

The solution of the governing equations is conducted on a non-uniform orthogonal grid system of $25 \times 40$ cells, in which small and dense cells are set in boundary areas, free 
Table 2. Basic system parameters, and initial and boundary conditions.

\begin{tabular}{|c|c|c|c|c|c|}
\hline Parameters & Unit & Value & Parameters & Unit & Value \\
\hline Depth of melt pool & $m$ & 3.57 & Dynamic viscosity of molten steel & $\mathrm{kg} \cdot \mathrm{m}^{-1} \mathrm{~s}^{-1}$ & $0.0062^{6)}$ \\
\hline Ladle internal diameter & $m$ & 3.58 & Specific heat of molten steel & $J \cdot \mathrm{kg}^{-1} \cdot \mathrm{K}^{-1}$ & $755^{6)}$ \\
\hline Diameter of gas orifice & $m$ & 0.015 & $\begin{array}{l}\text { Thermal conductivity of molten } \\
\text { steel }\end{array}$ & $W \cdot m^{-1} \cdot K^{-1}$ & $41^{6)}$ \\
\hline Flow rate of Ar gas & $m^{3} \cdot \min ^{-1}$ & 0.48 & Molar volume of alumina & $m^{3} \cdot \mathrm{mol}^{-1}$ & $34.33 \times 10^{-633)}$ \\
\hline Density of steel & $\mathrm{kg} \mathrm{m}^{-3}$ & $\begin{array}{l}7010-0.883^{*} \\
(\mathrm{~T}-1526)^{44)}\end{array}$ & $\begin{array}{l}\text { Interfacial tension } \sigma \text { between } \alpha \text { - } \\
\text { alumina and molten steel }\end{array}$ & $N . m^{-1}$ & $0.5^{34,47)}$ \\
\hline Density of Ar gas & $\mathrm{Kg} \cdot \mathrm{m}^{-3}$ & 0.933 & Initial oxygen in the melt & ppm & 300 \\
\hline Density of Alumina inclusions & $\mathrm{Kg} \cdot \mathrm{m}^{-3}$ & $3260^{45)}$ & Heat loss through ladle walls & $W m^{-2}$ & $12500^{6)}$ \\
\hline $\begin{array}{l}\text { Diffusion coefficient of oxygen in } \\
\text { molten steel }\end{array}$ & $m^{2} \cdot s^{-1}$ & $\left.2.7 \times 10^{-9} 45\right)$ & Heat loss through ladle bottom & $W m^{-2}$ & $12500^{6)}$ \\
\hline $\begin{array}{l}\text { Standard free energy change for } \\
2[\mathrm{Al}]+3[\mathrm{O}]=\mathrm{Al}_{2} \mathrm{O}_{3}\end{array}$ & J.mol ${ }^{-1}$ & $\begin{array}{l}1,225,000- \\
393.8 T^{46)}\end{array}$ & Heat loss through free surface & $W m^{-2}$ & 0 \\
\hline
\end{tabular}

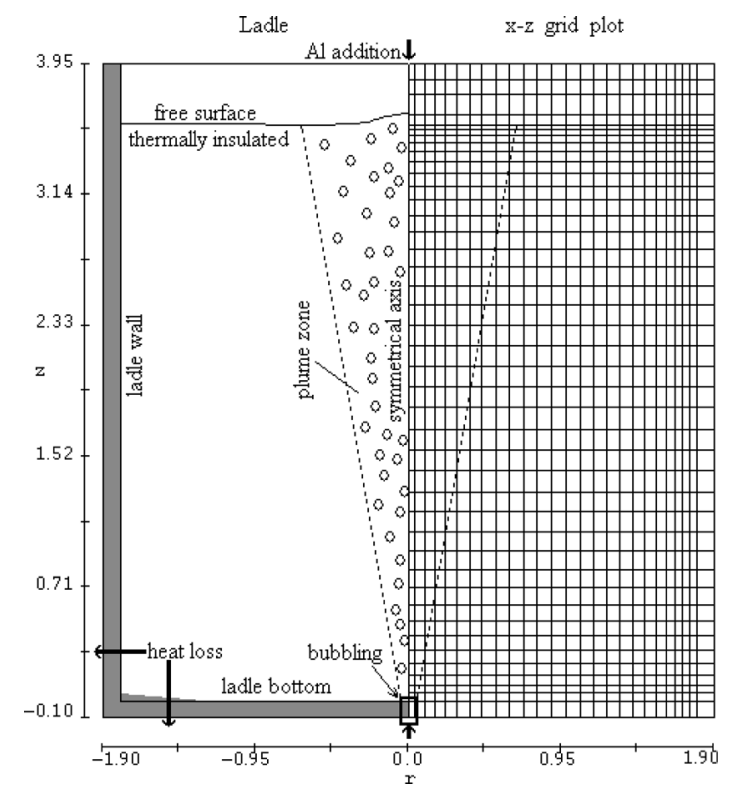

Fig. 2. Illustration of a gas-stirred steel ladle and the 2-D mesh system for computation (a non-uniform orthogonal grid mesh: $25 \times 40)$.

surface region and the plume region as shown in the right part of Fig. 2. A typical calculation needs roughly $100 \mathrm{~h}$ of CPU time on a $3.0 \mathrm{GHz} \mathrm{PC}$ to simulate $13 \mathrm{~min}$.

\subsection{Results of Simulations}

\subsubsection{Predicted Fluid Flow in the Ladle}

A typical simulated flow patterns is presented in Fig. 3. The left part of Fig. 3 shows the local flow direction and velocities of the ladle $3 \mathrm{~min}$ after the start of argon gas bubbling. The right side of Fig. 3 gives several streamlines of the melt, which clearly draw a map of steel recirculation. A maximum velocity of $1.55 \mathrm{~m} \cdot \mathrm{s}^{-1}$ of the melt is reached in the two-phase (melt and gas bubble) area. The steel stream changes the direction and flows radially outwards in the vicinity of the free surface. It is then directed towards the

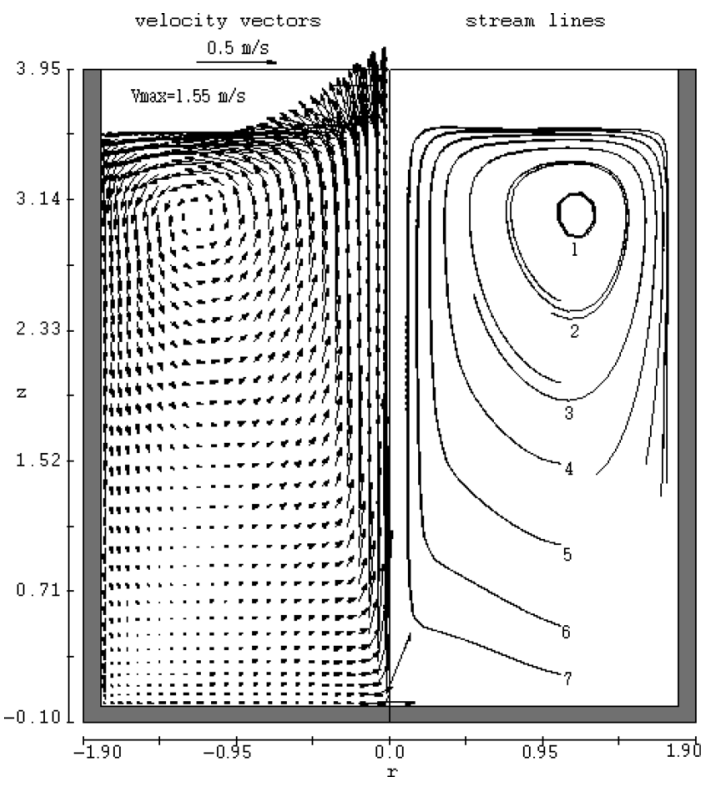

Fig. 3. Predicted flow patterns (left side) and streamlines (right side) in the melt bath of a 250 -ton ladle $300 \mathrm{~s}$ after the start of argon gas bubbling.

sidewall and descends further along the wall. Thus a fullscale circulation is established in the domain with a vortex eye located in the upper region near the ladle wall. Apparently, the velocities in the center two-phase area and free surface area are much higher than others.

\subsubsection{Mixing and Al-O Chemical Reaction}

A block of aluminum equivalent to $492 \mathrm{ppm}$ bulk-averaged concentration is plunged into a steel bulk having a uniform oxygen concentration of $300 \mathrm{ppm} 3 \mathrm{~min}$ after the bubbling starts. The change of concentration distribution of aluminum and free oxygen is illustrated in Figs. 4(a)-4(c), corresponding to $30 \mathrm{~s}, 60 \mathrm{~s}$ and $120 \mathrm{~s}$ after the aluminum addition. The left-hand side of each figure shows Al concentration contours while that of $\mathrm{O}$ in the right side. The 


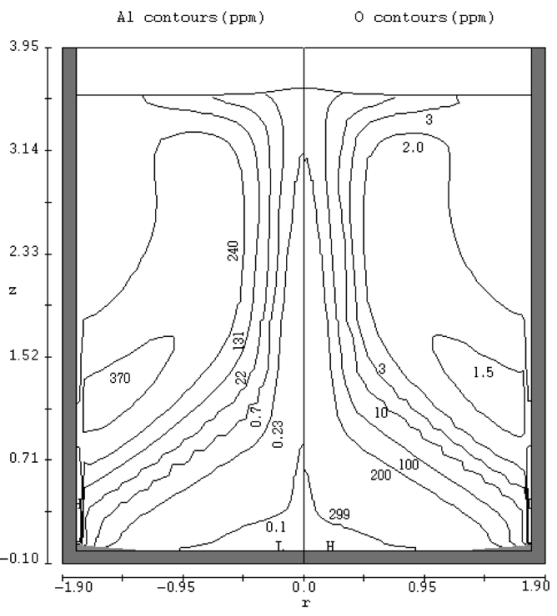

(a) $30 \mathrm{~s}$

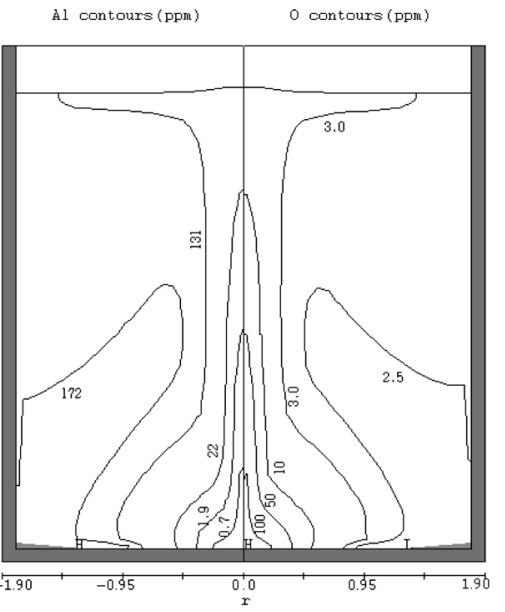

(b) $60 \mathrm{~s}$

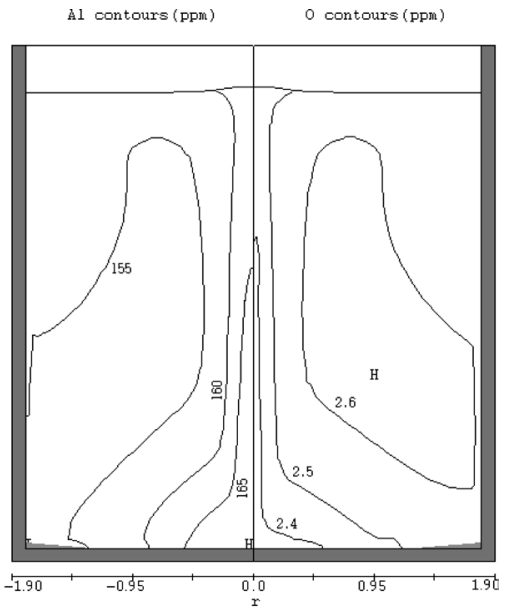

(c) $120 \mathrm{~s}$

Fig. 4. Predicted concentration contours for $\mathrm{Al}$ and $\mathrm{O}$ distribution in the melt bath of a 250 -ton ladle $30 \mathrm{~s}$ (a), $60 \mathrm{~s}$ (b) and $120 \mathrm{~s}$ (c) after aluminum addition.

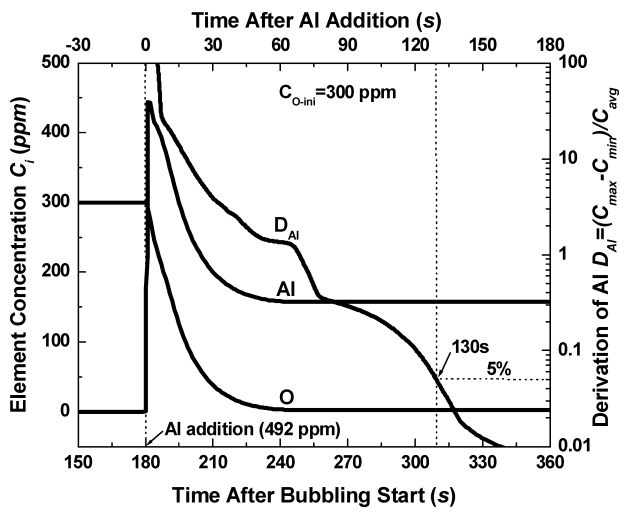

Fig. 5. History of bulk-averaged concentration of $\mathrm{Al}$ and $\mathrm{O}$.

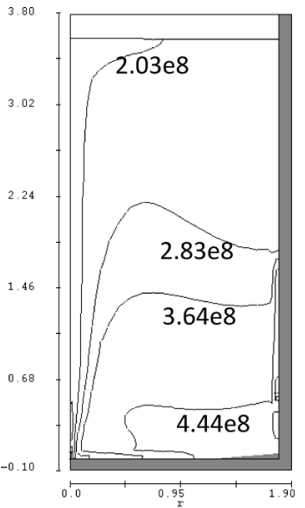

(a) $1 \mathrm{~min}$

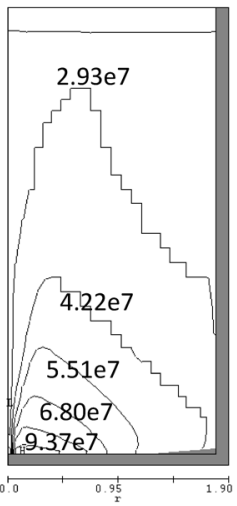

(b) $3 \mathrm{~min}$

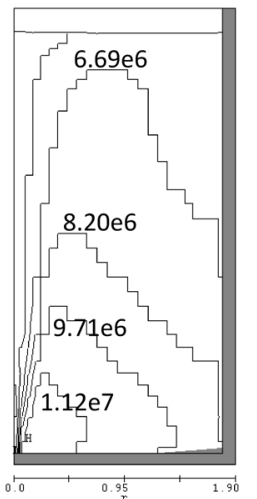

(c) $5 \mathrm{~min}$

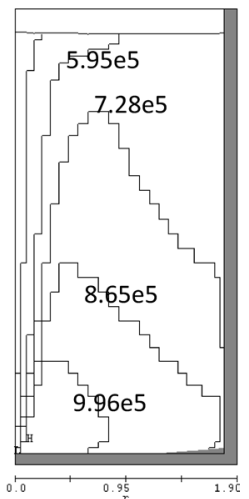

(d) $10 \mathrm{~min}$

Fig. 6. Prediction of space-dependent number density of $1 \mu \mathrm{m}$ inclusions $1 \mathrm{~min}$, $3 \mathrm{~min}, 5 \mathrm{~min}$, and $10 \mathrm{~min}$ after aluminum addition $\left(\mathrm{n} / \mathrm{cm}^{3}\right)$.

concentration distribution indicates that when $\mathrm{Al}$ is added into the steel melt, it is dissolved and pushed aside to the ladle sidewall, joining the recirculation flow of molten steel and simultaneously reacting with $\mathrm{O}$. Consequently, in the early stage of deoxidation, a high concentration of $\mathrm{Al}$ and low concentration of $\mathrm{O}$ may appear in the upper part near the sidewall in the ladle bulk, as shown in Fig. 4(a). However, as the time goes, the vicinity of the gas orifice shows to have low $\mathrm{O}$ and high $\mathrm{Al}$.

The history of the bulk-averaged concentration of $\mathrm{Al}$ and $\mathrm{O}$ is presented in Fig. 5, where the lower $x$-axis represents the bubbling time, and the upper $x$-axis the time after the Al addition, while the left $y$-axis stands for the element concentration, and the right $y$-axis for $D_{A l}$ the deviation of $\mathrm{Al}$ concentration from completely mixed state. The mixing rate is increased significantly during 60-75 s after Al addition, which means it takes about $60 \mathrm{~s}$ for $\mathrm{Al}$ element reach to gas plume zone and about $15 \mathrm{~s}$ to scatter into entire ladle. If a characterizing mixing efficiency, i.e., mixing time $t_{m}$ according to the so-called ' $5 \%$ criteria', ${ }^{14)}$ is defined as the time after which the deviation of $\mathrm{Al}$ concentration everywhere in the ladle from the bulk-averaged concentration is less than $5 \%$, a mixing time of about $130 \mathrm{~s}$ is found when the gas injection rate $Q=0.48 \mathrm{~m}^{3} \cdot \mathrm{min}^{-1}$. At $t=10.0 \mathrm{~min}$,
$157 \mathrm{ppm}$ aluminum comes into approximate equilibrium with $2.5 \mathrm{ppm}$ free oxygen at $1556^{\circ} \mathrm{C}$ in terms of the bulkaveraged variables.

In fact, the mixing process of $\mathrm{Al}$ and $\mathrm{O}$ is the consequence of a combined action involving mass convection, diffusion and consumption due to chemical reaction. $\mathrm{Nu}-$ merical computation reveals that a rapid and effective mass homogenization can be expected if the deoxidation process proceeds under the condition of a fully developed flow pattern.

\subsubsection{Time- and Space-dependent PSDs of Inclusions}

Particles ranging from a few nanometers to fifty micrometers in diameter are traced in the simulation. Some typical results are described in Fig. 6, which present the distribution contours of number density in the unit of $\mathrm{n} \cdot \mathrm{cm}^{-3}$ for $1 \mu \mathrm{m}$ in diameter at $1 \mathrm{~min}, 3 \mathrm{~min}, 5 \mathrm{~min}$, and $10 \mathrm{~min}$ after aluminum addition.

It is noted that, as shown in Fig. 6, the area of high number density for $1 \mu \mathrm{m}$ particle is located near the ladle bottom. In addition, the vicinity of the gas nozzle in the plume zone is found to exhibit a sharp population density gradient. Regarding the distribution of turbulent energy and its dissipation rate in the corresponding region, as seen in Fig. 


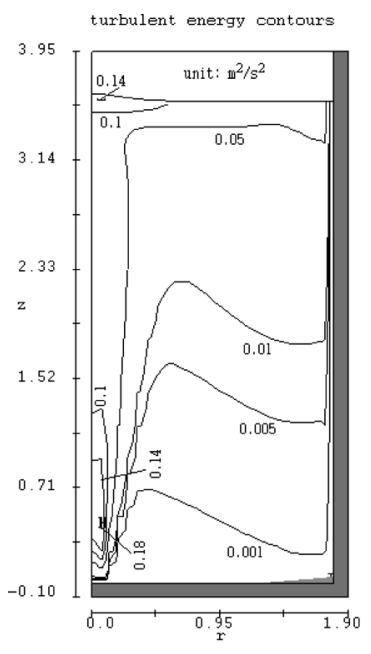

(a)

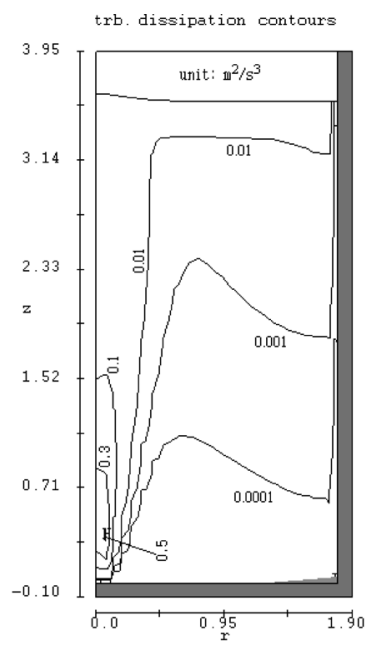

(b)

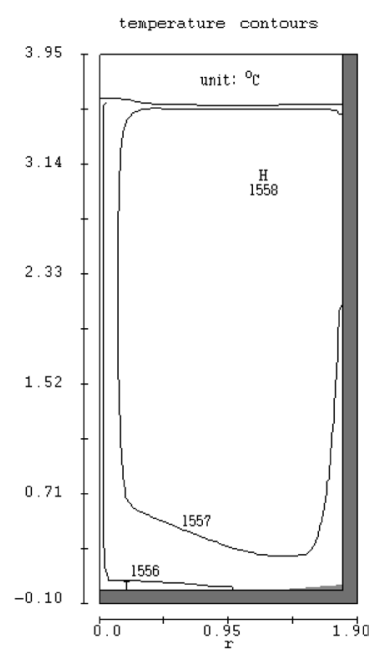

(c)

Fig. 7. Predicted turbulent energy (a), dissipation rate of turbulent energy (b), and temperature distribution (c) in the melt bath of a 250-ton ladle $300 \mathrm{~s}$ after the start of argon gas bubbling.

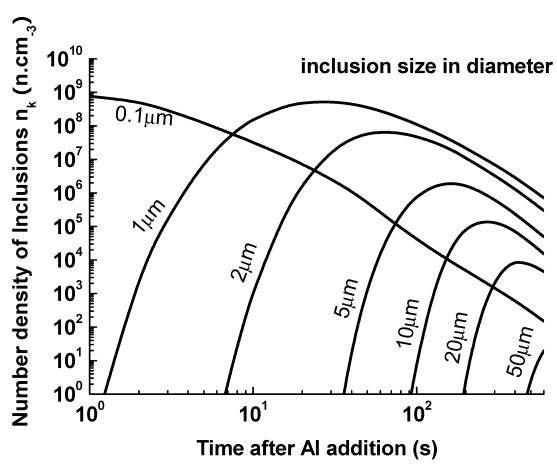

(a) PSDs with bubble-inclusion attachment

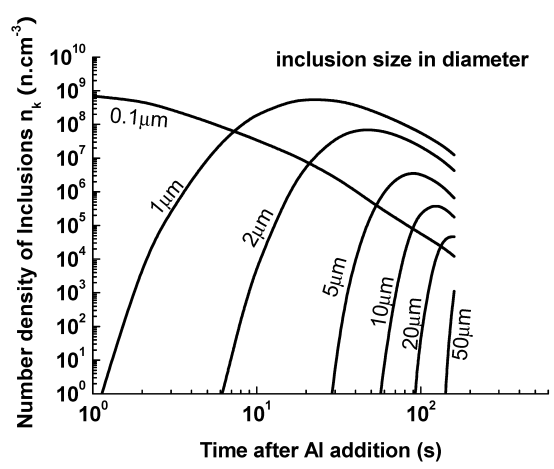

(b) PSDs without bubble-inclusion attachment

Fig. 9. Evolution of bulk-averaged number density of different size inclusions.

7, the high turbulent energy generation and dissipation in the area, several hundred times the average level, intensifies the mixing and increases the possibility of inclusion collisions. Simultaneously, bubble-inclusion attachment increases the possibility of inclusion removal.

Figure 8 presents simulated results of bulk-averaged PSDs at various time intervals after $\mathrm{Al}$ addition. To reveal the effect of bubble-inclusion attachment, simulation results which ignore the removal by the bubble attachment are also included in Fig. 8 and Figs. 9-11.

Up until $30 \mathrm{~s}$ after the $\mathrm{Al}$ addition, inclusions are mostly

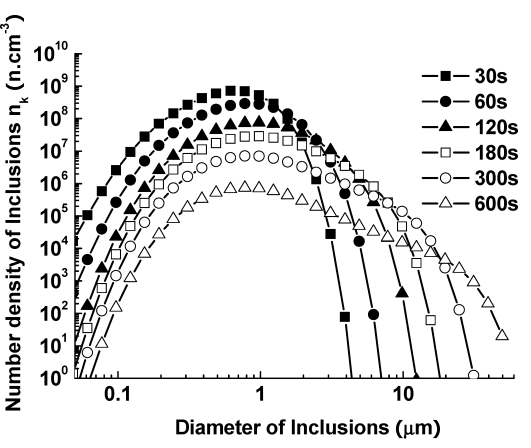

a) PSDs with bubble-inclusion attachment

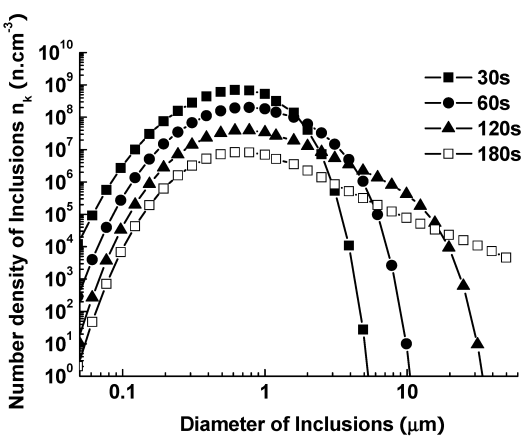

(b) PSDs without bubble-inclusion attachment

Fig. 8. Prediction of bulk-averaged PSDs at various time moments.

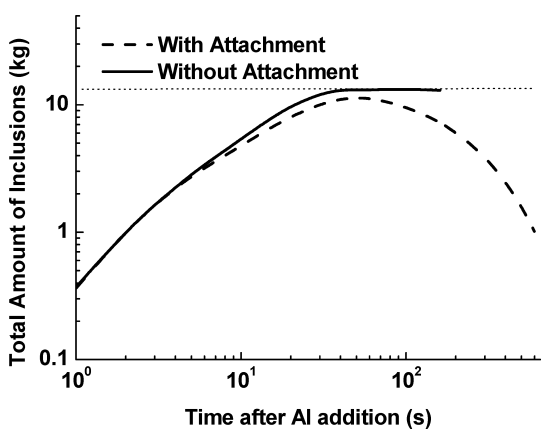

Fig. 10. Comparison of total amount of inclusions in the ladle with and without bubble-inclusion attachment.

smaller than $4 \mu \mathrm{m}$ in diameter, as shown in Fig. 8(a). During 30 to $120 \mathrm{~s}$, the population of $4-10 \mu \mathrm{m}$ inclusion increases significantly. During 120 to $600 \mathrm{~s}$, the population of $10-50 \mu \mathrm{m}$ increases. When the bubble-inclusion attachment is neglected, the growth of inclusion becomes faster. Within $30 \mathrm{~s}$ after the $\mathrm{Al}$ addition, the inclusions are smaller than $5 \mu \mathrm{m}$ in diameter, as shown in Fig. 8(b). During 30 to $120 \mathrm{~s}$, the population of 5-30 $\mu \mathrm{m}$ inclusion increases significantly. At $180 \mathrm{~s}$, the population of $50 \mu \mathrm{m}$ becomes popular already.

Figure 9 presents the simulated results of bulk-averaged PSDs at various inclusion sizes, as shown in Fig. 9(a). Within $1 \mathrm{~s}$ after $\mathrm{Al}$ addition, the inclusion of $0.1 \mu \mathrm{m}$ in diameter is already popular. $1 \mu \mathrm{m}$ inclusions are appeared at $1.2 \mathrm{~s}, 10 \mu \mathrm{m}$ inclusions are appeared at $90 \mathrm{~s}$, and $50 \mu \mathrm{m}$ inclusions are appeared at $460 \mathrm{~s}$. When the bubble-inclusion attachment is neglected, the growth of inclusion becomes faster, as shown in Fig. 9(b). $10 \mu \mathrm{m}$ inclusions are appeared at $57 \mathrm{~s}$, and $50 \mu \mathrm{m}$ inclusions are appeared at $150 \mathrm{~s}$. 


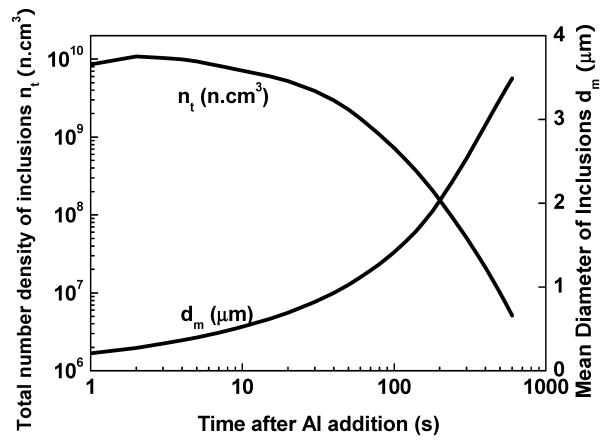

(a) PSDs with bubble-inclusion attachment

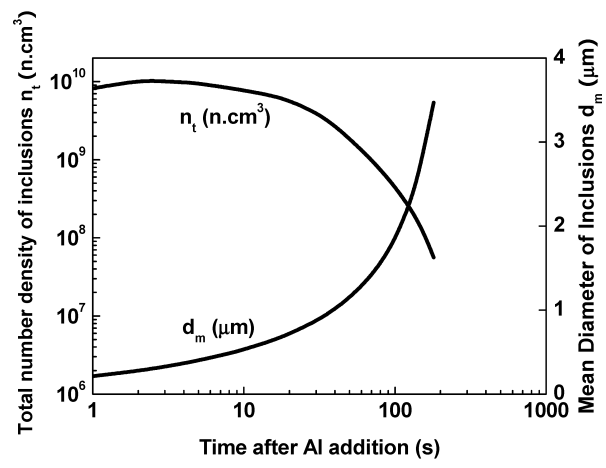

(b) PSDs without bubble-inclusion attachment

Fig. 11. Variation of bulk-averaged total number density of inclusions and mean inclusion size as a function of time.

Figure 10 presents total amount of inclusions in the ladle. The dot line describes the theoretical maximum value of amount of inclusions, i.e. $13.2 \mathrm{~kg}$ of $\mathrm{Al}_{2} \mathrm{O}_{3}$, and total amount of inclusions have a peak within $40 \mathrm{~s}$ after $\mathrm{Al}$ addition. After $40 \mathrm{~s}$, the total amount decreases by the inclusion removal process, especially bubble-inclusion attachment. It is observed by the analysis of numerical simulations that the $99 \%$ of the total inclusion removal is by the bubble-inclusion attachment, and wall attachment and Stokes's flotation has less than $1 \%$. For that reason, when the bubble-inclusion attachment is ignored, the total amount of inclusion is difficult to be decreased as shown at solid line in Fig. 10.

Based on the time- and space-dependent PSDs predicted by the present model, Fig. 11 describes total inclusion number density $n_{t}\left(\mathrm{n} \cdot \mathrm{cm}^{-3}\right)$, and mean diameter $d_{m}(\mu \mathrm{m})$ which is calculated from mean volume of inclusion defined as total inclusion volume divided by the population of inclusions. The mean particle diameter is increasing as the total number density is decreasing with time, which means the inclusion growth. When the bubble-inclusion attachment is ignored, the growth becomes faster as shown in Fig. 11(b).

\section{Discussion}

\subsection{On the Numerical Calculation Techniques}

Theoretical and practical experiences indicate that particle size spectrum during the nucleation and the growth of inclusions expands very rapidly, from angstrom to micrometer in size. Consequentially, the dimension of the set of differential equations is large, and a numerical calculation is practically not possible if one's interest extends to particles beyond a few nanometers. In order to overcome this

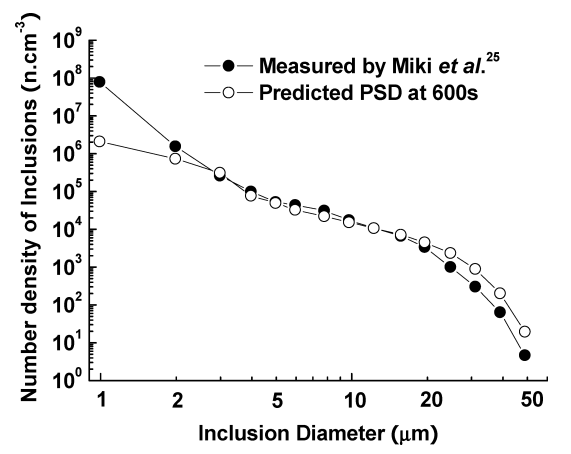

Fig. 12. Comparison of predicted PSD trend $10 \mathrm{~min}$ after aluminum addition with industrial data measured in a ladle at the start of casting.

difficulty, several approximate numerical methods have been developed, including the so-called Discrete-Sectional method $^{48-50)}$ and the Particle-Sizing-Grouping (PSG) method. ${ }^{51)}$ A modified approach, i.e., the DS method, was developed previously by the present authors. ${ }^{37)}$ In addition, the modeling practice indicates that the numerical time interval must be as small as the order of $10^{-10}-10^{-6} \mathrm{~s}$, in order to ascertain a convergent solution of nucleation. This gives an added load of computational time. In the present dynamic model, this difficulty was overcome by preparing a table which covers the evolution of PSDs under various thermodynamic and kinetic conditions. In the course of the model operation, the table is looked up whenever necessary. With this approximate technique, a numerical solution to the CFD-based inclusion model has become possible.

\subsection{Comparison of Predicted PSDs with Experimental Observation}

Miki and Thomas ${ }^{25)}$ reported their measurements of PSD with a sample taken at the melt $0.5 \mathrm{~m}$ lower from the top surface of a $160 \mathrm{t}$ steel ladle. Even though the size and the operation condition of ladle are not same, it can be expected that the trend of PSD in the ladle will be similar. The trend of PSD with bubble attachment predicted by the present model is compared with their data in Fig. 12. A strikingly good agreement is seen in the figure except a small deviation for small inclusions. The difference may be attributed to the fact that the effect of reoxidation of molten steel is ignored in the modeling prediction and inconsistency in operation conditions may have existed.

\subsection{On the Collision Growth of Inclusions}

Nucleation and growth of inclusions in Al-deoxidized molten steel are represented in Fig. 13 in which importance of various inclusion growth mechanisms at different times are visible. Ostwald ripening is the prevailing mechanism for growth at the initial stage immediately after nucleation. Brownian collision then predominates followed by turbulent coagulation in the case of efficient agitation. At later stages, inclusion growth is primarily attributed to the joint effort of both turbulent collisions and Stokes collisions. However, the gradient collisions which take place in laminar shear regions near walls is unusual that it can be ignored during the entire deoxidation process, so it will not be evaluated during the CFD-based dynamic modeling. 


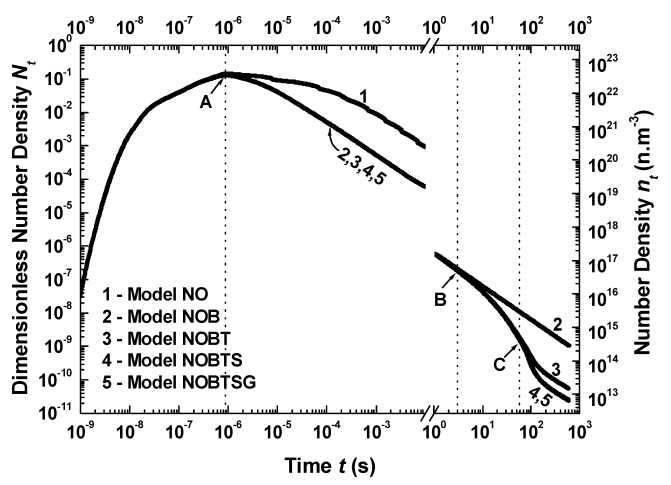

Fig. 13. Contribution of various inclusion growth approaches to the change of total number density of inclusions $(\mathrm{N}$, nucleation; O, Ostwald ripening; B, Brownian collision; T, turbulent collision; S, Stokes collision; G, gradient collision).

\subsection{On the Bubble-Inclusion Attachment}

In Fig. 14, the effect of the bubble-inclusion attachment is made more visible. In both cases (with and without attachment) the number density decrease after passing the peak, but much faster decrease in the case of the attachment. This effect becomes more pronounced as the time increases (Figs. 13(c) and 13(d)). The difference between the two curves in these figures indicates the decrease in the number density due to the bubble attachment.

\section{Conclusions}

On the platform of computational fluid dynamics, a general model, termed a CFD-based nucleation-growth-removal model, has been mathematically established to account for the nucleation, growth and removal of inclusions under the condition of gas agitation. A Eulerian-Lagrangian CFD model accompanied by the $\kappa-\varepsilon$ two-equation turbulence model is used to predict the turbulent recirculation induced by bottom-blown gas injection, temperature evolution, time-dependent element concentration distribution, and particle transport. As to the formation and growth of inclusions in the steel melt, the model includes the contribution of homogeneous nucleation, diffusion growth and Ostwald ripening. Various collision-coagulation growth mechanisms, Brownian collision, turbulent collision and Stokes collision were also considered. In addition, the model estimated inclusion removal by the function of Stokes flotation, wall adherence and bubble-inclusion attachment. The DS numerical method ${ }^{34)}$ developed by the present authors and data-look-up scheme were adopted to save the computational time. As a function of the comprehensive model, prediction of time- and space-dependent PSDs can be conducted directly from an initial concentration of $\mathrm{Al}$ and $\mathrm{O}$ rather than an initial size of inclusions.

The model is applied to the aluminum deoxidation process in a steel ladle with argon bubbling. The model simulated the transient flow of molten steel, predicting the time-dependent contours of some scalar parameter, i.e., turbulent energy $k$, dissipation rate of turbulent energy $\varepsilon$ and melt temperature. A mixing time of $130 \mathrm{~s}$ according to ' $5 \%$ criteria' together with time-dependent concentration distribution has been predicted for the $\mathrm{Al} / \mathrm{O}$ mixing process in-

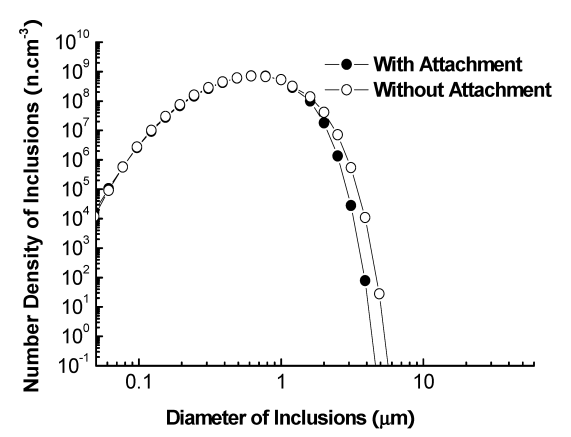

(a) $30 \mathrm{~s}$ after $\mathrm{Al}$ addition

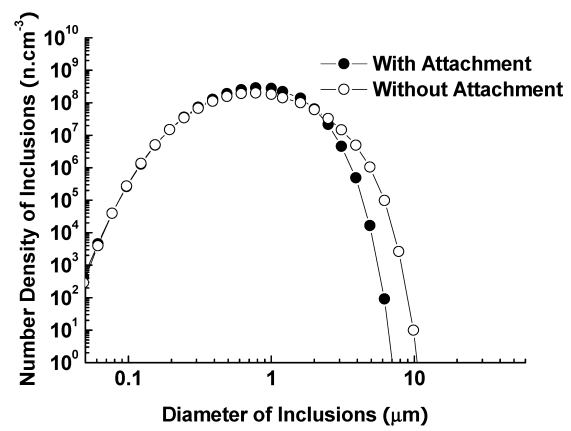

(b) $60 \mathrm{~s}$ after $\mathrm{Al}$ addition

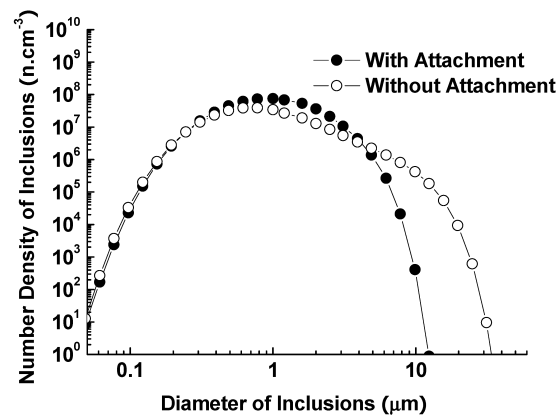

(c) $120 \mathrm{~s}$ after $\mathrm{Al}$ addition

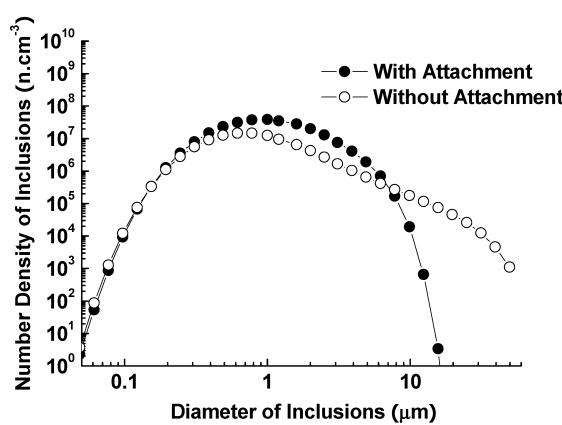

(d) $160 \mathrm{~s}$ after $\mathrm{Al}$ addition

Fig. 14. Comparison of PSDs with and without attachment at $30 \mathrm{~s}, 60 \mathrm{~s}, 120 \mathrm{~s}$ and $160 \mathrm{~s}$ after $\mathrm{Al}$ addition.

volving mass diffusion, convection and the chemical reaction. Numerical investigation indicates that stable recirculation of steel melt, thermal and mass homogenization can be efficiently gained through gas bubbling.

As to the evolution of inclusion behaviors induced by nucleation, diffusion, Ostwald repining, collision growth and various removal approaches, time- and space-dependent inclusion size distributions have been released. The present model shows a good consistency of particle size distributions with the reported data collected under industrial conditions. The effect of bubble on the growth and removal of 
inclusion is also discussed.

\section{Nomenclature}

$A_{k}: \quad$ Surface area of a $k$-size particle $\left(\mathrm{m}^{2}\right)$

$C_{i}$ : Concentration of element $i$ in molten steel (ppm)

$C_{\mu}$ : Constant used in the $\kappa-\varepsilon$ two-equation turbulence model

$h$ : local fluid height

$i_{c}$ : critical size of particle

$N$ : Number of bubble-inclusion collision

$n_{1}$ : Number density of monomers $\left(\mathrm{n} \cdot \mathrm{m}^{-3}\right)$

$n_{k}$ : Number density of $k$-size particles $\left(\mathrm{m}^{-3}\right)$

$P_{C}$ : Probability of collision

Re: Reynolds number

$r_{b}:$ Radius of bubble (m)

$r_{p}:$ Radius of inclusions (m)

$S_{p}^{C}$ : source term of particle growth

$S_{p}^{N O}$ : Source term for particle nucleation and growth due to diffusion and Ostwald ripening

$S_{p}^{F}$ : Source term for particle removal by flotation

$S_{p}^{W A}$ : Source term for particle removal by wall attachment

$t$ : Time (s)

$u_{p}:$ Velocity of particle $\left(\mathrm{m} \cdot \mathrm{s}^{-1}\right)$

$v_{b}$ : Velocity of bubble $\left(\mathrm{m} \cdot \mathrm{s}^{-1}\right)$

$y$ : Distance from the wall $(\mathrm{m})$

$y^{+}$: Dimensionless distance from the wall

$\alpha_{k}$ : Number of monomers dissociating from unit area of a $k$-size particle in unit time $\left(\mathrm{m}^{-2} \cdot \mathrm{s}^{-1}\right)$

$\beta_{1 k}$ : Rate constant of the reaction $(1)+(k) \rightarrow(1+k)$ $\left(\mathrm{m}^{3} \cdot \mathrm{s}^{-1}\right)$

$\beta_{i j}^{C}$ : Total collision frequency function

$\delta()$ : Delta function

$\delta$ : Turbulent boundary layer thickness (m)

$\delta_{t}$ : Calculation time step (s)

$\eta_{W A}$ : Removal efficiency of inclusions

$\kappa: \quad$ turbulent energy $\left(\mathrm{m}^{2} \cdot \mathrm{s}^{-2}\right)$

$v_{l}:$ Kinematic viscosity $\left(\mathrm{m}^{2} \cdot \mathrm{s}^{-1}\right)$

$\rho_{l}$ : Density of liquid phase $\left(\mathrm{kg} \cdot \mathrm{s}^{-3}\right)$

$\tau_{0}$ : Shear stress $\left(\mathrm{kg} \cdot \mathrm{m}^{-1} \cdot \mathrm{s}^{-2}\right)$

\section{REFERENCES}

1) B. E. Launder and D. B. Spalding: Comp. Meth. Appl. Mech. Eng., 3 (1974), 269.

2) T. DebRoy, A. K. Majumdar and D. B. Spalding: Appl. Math. Modell., 2 (1978), 146.

3) J. S. Joo, J. Szekely, A. H. Castillejos and J. K. Brimacombe: Metall. Trans. B, 21B (1990), 269.

4) D. Mazumdar, R. I. L. Guthrie and Y. Sahai: Appl. Math. Modell., 17 (1993), 255.

5) D. Mazumdar and R. I. L. Guthrie: Mater. Trans. B, 16B (1985), 83

6) A. H. Castillejos, M. E. Salcudean and J. K. Brimacombe: Metall. Trans. B, 20B (1989), 603.

7) J. S. Joo and R. I. L. Guthrie: Metall. Trans. B, 23B (1992), 765.

8) M. R. Malin and D. B. Spalding: Physicochem. Hydrodynam., 5
(1984), 339.

9) O. J. Ilegbusi and J. Szekely: ISIJ Int., 30 (1990), 731.

10) P. Jönsson and L. Jonsson: Scand. J. Metall., 24 (1995), 194.

11) J. L. Xia and T. Ahokainen: Scand. J. Metall., 32 (2003), 211.

12) H. Turkoglu and B. Farouk: ISIJ Int., 31 (1991), 1371.

13) S. T. Johansen and F. Boysan: Metall. Trans. B, 19B (1988), 755.

14) M. Neifer, S. Rödl and D. Sucker: Steel Res., 64 (1993), 54.

15) D. Mazumdar and R. I. L. Guthrie: ISIJ Int., 34 (1994), 384.

16) D. Guo and G. A. Irons: Metall. Trans. B, 31B (2000), 1457.

17) U. Lindborg and K. Torssell: Trans. Met. Soc. AIME, 242 (1968), 94.

18) R. K. Iyengar and W. O. Philbrook: Metall. Mater. Trans., 3 (1972), 1823.

19) S. Linder: Scand. J. Metall., 3 (1974), 137.

20) T. A. Engh and N. Lindskog: Scand. J. Metall., 4 (1975), 49.

21) K. Nakanishi and J. Szekely: Trans. Iron Steel Inst. Jpn., 15 (1975), 522.

22) K. Shirabe and J. Szekely: Trans. Iron Steel Inst. Jpn., 23 (1983), 465 .

23) Y. Miki, Y. Shimada, B. G. Thomas and A. Denissov: Iron Steelmaker, 24 (1997), August, 31.

24) H. Tozawa, Y. Kato, K. Sorimachi and T. Nakanishi: ISIJ Int., 39 (1999), 426.

25) Y. Miki and B. G. Thomas: Metall. Trans. B, 30B (1999), 639.

26) A. K. Sinha and Y. Sahai: ISIJ Int., 33 (1993), 556.

27) D.-Y. Sheng, M. Söder, P. Jönsson and L. Jonsson: Scand. J. Metall., 31 (2002), 134

28) M. Söder, P. Jönsson and J. Alexis: Scand. J. Metall., 31 (2002), 210

29) J. W. Christian: The Theory of Transformations in Metals and Alloys-PART I Equilibrium and General Kinetic Theory, 2nd ed., Pergamon Press, Oxford, London, (1975), 418.

30) M. L. Turpin and J. F. Elliott: J. Iron Steel Inst., 204 (1966), 217.

31) E. T. Turkdogan: J. Iron Steel Inst., 204 (1966), 914.

32) E. T. Turkdogan: J. Iron Steel Inst., 210 (1972), 21.

33) K. Mukai, H. Sakao and K. Sano: Trans. Iron Steel Inst. Jpn., 9 (1969), 196

34) L. Zhang and W. Pluschkell: Ironmaking Steelmaking, 30 (2003), 106.

35) W.-C. Doo, M.-J. Jang, S.-C. Kang and K.-W. Yi: Proc. of 85th Steelmaking Conf., ISS, Warrendale, PA, (2002), 477.

36) L. Kampmann and M. Kahlweit: Ber. Bunsenges. Phys. Chem., 74 (1970), 456

37) J. Zhang and H.-G. Lee: ISIJ Int., 44 (2004), 1629.

38) M. v. Smoluchowski: Z. Phys. Chem., 92 (1917), 129

39) S. K. Friedlander and C. S. Wang: J. Colloid Interface Sci., 22 (1966), 126

40) P. G. Saffman and J. S. Turner: J. Fluid Mech., 1 (1956), 16.

41) V G. Levich: Physicochemical Hydrodynamics, Prentice-Hall, Inc., Englewood Cliffs, N J, 211.

42) Y. J. Kwon, J. Zhang and H. G. Lee: ISIJ Int., 46 (2006), 257.

43) F. Frisvold, T. A. Engh, S. T. Johansen and T. Pedersen: Light Metals, The Minerals, Metals \& Materials Society, USA, (1992), 1125.

44) S. Chakraborty and Y. Shahai: Metall. Trans. B, 23B (1992), 153.

45) Y. Kawai and Y. Shiraishi: Handbook of Physico-chemical Properties at High Temperature, ISIJ, Tokyo, (1988), 188.

46) The Japan Society for the Promotion of Science: Steelmaking Data Sourcebook, Gordon and Breach Science Publishers, New York, (1988), 45

47) K. Wasai and K. Mukai: Metall. Trans. B, 30B (1999), 1065.

48) G. Gelbrad and J. H. Seinfild: J. Comput. Phys., 28 (1978), 357.

49) G. Gelbard, Y. Tambour and J. H. Seinfeld: J. Colloid Interface Sci., 76 (1980), 541.

50) J. J. Wu and R. C. Flagan: J. Colloid Interface Sci., 123 (1988), 339.

51) T. Nakaoka, S. Taniguchi, K. Matsumoto and S. T. Johansen: ISIJ Int., 41 (2001), 1103. 